\title{
Prevalence of obsessive-compulsive disorder in Iran
} Mohammad Reza Mohammadi*1,2, Ahmad Ghanizadeh1, Mehdi Rahgozar³, Ahmad Ali Noorbala1, Haratoun Davidian1, Hossein Malek Afzali ${ }^{4}$, Hamid Reza Naghavi' ${ }^{1}$ Seyed Abbas Bagheri Yazdi ${ }^{5}$, Seyed Mehdi Saberi6, Bita Mesgarpour ${ }^{2}$, Shahin Akhondzadeh ${ }^{1}$, Javad Alaghebandrad ${ }^{1}$ and Mehdi Tehranidoost ${ }^{1}$

\begin{abstract}
Address: ${ }^{1}$ Psychiatry and Clinical Psychology Research Center, Tehran University of Medical Sciences, Roozbeh Hospital, South Kargar St., 13185 1741, Tehran, Iran, ${ }^{2}$ National Research Center of Medical Sciences, No. 26, 1st Al., Kooh-e-Noor St., Motahhari Ave., Tehran, Iran, ${ }^{3}$ Tarbiat Modarres University, University of Social Welfare and Rehabilitation, Tehran, Iran, ${ }^{4}$ Department of Biostatistics and Epidemiology, School of Public Health, Tehran University of Medical Sciences, Tehran, Iran, ${ }^{5}$ Youth and School Health Department, Mental Health Unit, Ministry of Health and Medical Education, Tehran, Iran and ${ }^{6}$ Medicine Legal Organisation, Tehran, Iran

Email: Mohammad Reza Mohammadi* - mrmohammadi@yahoo.com; Ahmad Ghanizadeh - ghanizad@sina.tums.ac.ir; Mehdi Rahgozar - rahgozar@modares.ac.ir; Ahmad Ali Noorbala - noorbala@irrcs.org; Haratoun Davidian - davidian@sina.tums.ac.ir; Hossein Malek Afzali - afzali@hbi.ir; Hamid Reza Naghavi - naghavi@iricss.org; Seyed Abbas Bagheri Yazdi - sabagheri@yahoo.com; Seyed Mehdi Saberi - saberi_md@hotmail.com; Bita Mesgarpour - mesgarpur@nrcms.org; Shahin Akhondzadeh - s.akhond@neda.net; Javad Alaghebandrad -rad@ams.ac.ir; Mehdi Tehranidoost - tehranid@sina.tums.ac.ir

* Corresponding author
\end{abstract}

This article is available from: http://www.biomedcentral.com/l47I-244X/4/2

(C) 2004 Mohammadi et al; licensee BioMed Central Ltd. This is an Open Access article: verbatim copying and redistribution of this article are permitted in all media for any purpose, provided this notice is preserved along with the article's original URL.

\begin{abstract}
Background: Estimates of the annual prevalence for Obsessive Compulsive Disorder (OCD) were consistent across the international sites range, $1.9 \%-2.5 \%$. The nine population surveys, which used Diagnostic Interview Schedule, estimated a six-month prevalence of OCD ranging from $0.7 \%$ to $2.1 \%$.

This study performed in order to determine the prevalence of OCD in a population-based study among Iranian adults aged 18 and older and to study the association of them with factors such as sex, marital status, education, type of occupation and residential area.

Methods: A cross-sectional nationwide epidemiological study of the Iranian population aged 18 and older was designed to estimate the prevalence of psychiatric disorders and their association with the above mentioned factors. 25/80 individuals were selected and interviewed through a randomized systematic and cluster sampling method from all Iranian households. Schedule for Affective Disorders and Schizophrenia (SADS) and Diagnostic and Statistical Manual of Mental Disorders-IV (DSM-IV) criteria were used in diagnosis of OCD. 250 clinical psychologists interviewed the selected subjects face to face at their homes.

Results: The prevalence of OCD in Iran is $1.8 \%$ (0.7\% and $2.8 \%$ in males and females; respectively). $50.3 \%$ of the survey sample were men, $49.9 \%$ women, $29.1 \%$ single, $67.45 \%$ married, $0.4 \%$ separated or divorced, $2.5 \%$ widow/widower and $4 \%$ undetermined. All of the above-mentioned factors were examined in the univariate and multivariate logistic regression models. Although the data did not fit the models well, but in univariate models, sex, the category "single" of marital status, age, the categories "business" and "housewife" and residential areas showed significant effect adjusting for the factors, but the models didn't fit the data properly.
\end{abstract}


Conclusion: The study suggests that the prevalence of OCD is not rare in the community of Iran and is within the range of other countries. Similar to prior studies in other communities, OCD is more common in females than males.

\section{Background}

In general, epidemiological studies provide much different view of Obsessive Compulsive Disorder (OCD) than that obtained among OCD patients in clinical samples. Many, if not most, of the subjects who participate in epidemiological studies are not actually seeking treatment, or are not aware of the fact that they did not know they have OCD. In contrast with, clinical samples are generally seeking treatment.

OCD was thought to be extremely rare in the community, as low as five per 1000 [1] or five per 10,000 [2], hence the importance and prevalence of OCD has been underestimated for many decades.

In a survey in Canada, the lifetime prevalence was $2.9 \%$ in adults [3]. The nine population surveys, which used Diagnostic Interview Schedule (DIS), estimated a six-month prevalence of OCD ranging from $0.7 \%$ to $2.1 \%$ [4]. The Epidemiological Catchment Area (ECA) study, which was a home-to-home household survey of more than 30,000 people in the United States, estimated that the lifetime prevalence rate for OCD was a robust 2-3\% [5]. This rate suggests that OCD is twice as common as schizophrenia or panic disorder. Moreover, the ECA study estimates that OCD represents the fourth most common psychiatric disorder in the USA. Another study assessed the prevalence of OCD in six other countries (Canada, Germany, Korea, New Zealand, Puerto Rico, and Taiwan) [6]. Estimates of the annual prevalence rates for OCD were fairly consistent across the international sites (range, 1.9 - 2.5 per 100) and remarkably comparable to the prevalence rates reported for the USA from Karno et al's study data [5]. Taiwan had a relatively low prevalence rate of OCD (0.7) 100). Therefore, OCD exists as a fairly common psychiatric disorder throughout the whole world [6]. Some literatures report an equal sex distribution of OCD $[7,8]$.

It was reported that the prevalence of OCD is highest among persons who are single compared to those married [9]. There are some inconsistencies in previous studies and a low rate of OCD is reported in Asian countries. Therefore, it may still be important to study the prevalence of OCD in other countries.

This study was conducted in 2001 in order to estimate the lifetime prevalence of OCD and other psychiatric disorders in the general population of Iran also, to study the association with demographic factors. It is a novel study in Iran and to our knowledge is the first, which has dealt with a sample representative of the total adult population of Iran.

\section{Methods}

A cross-sectional population-based epidemiological study of the Iranian adults, aged 18 and older, was designed to estimate the prevalence of psychiatric disorders and their association with some demographic factors.

From 12,398,235 households residing in Iran, 7795 families were selected by randomized systematic and cluster sampling from 1559 clusters, 997 clusters were in urban and 582 in rural areas, each cluster with 5 households were studied. The total number of the subjects whom were interviewed and completed the Schedule for Affective Disorders and Schizophrenia (SADS) was 25180 subjects in the year 2001. Out of 27698 individuals, 25180 completed the interview. The responds rate was $90 \%$.

The widely known instrument, the structured interview of SADS [10] was used to obtain OCD by Diagnostic and Statistical Manual of Mental Disorders-IV (DSM-IV) criteria [11]. A structured instrument ascertains the diagnosis of psychiatric disorders. Its reliability and validity has previously been reported [12].

The screening and diagnosis of disorders could be made based on the findings of this schedule in one stage. The SADS questions were translated to Farsi, then converted in to English by two bilinguals and after the confirmation of translation, the questionnaire was ready for the result of the test performance.

In the direction of studying the validity of the content of the questions, the test questionnaire was studied by a number of psychiatric authorities, and was considered after eliminating the defects, adjusting the main form and conducting the constructing validity and predictive validity tests on 200 existing patients of Roozbeh hospital, which already had a psychiatric diagnosis. On co-rated interviews, there was a high agreement between interviewers for diagnosing OCD. For test-retest interviewers, the Cohen Kappa coefficient was 0.87. The Cohen Kappa coefficients for other anxiety disorders, mood disorders, and psychotic disorders were $0.79,0.88$, and 0.91 respectively. In cases of dissociative disorders, personality disorders, and drug abuse, the Cohen Kappa coefficient was about 0.45 . 
Table I: Prevalence of OCD by sex, age group and marital status.

\begin{tabular}{|c|c|c|c|}
\hline Variable & & $\%(n)$ & $p$ \\
\hline \multirow[t]{3}{*}{ Sex } & $M(n: 12628)$ & $0.7(91)$ & $X^{2}=160.03, d f=I, P=0.001$ \\
\hline & $F(n: 12520)$ & $2.8(353)$ & \\
\hline & $\mathrm{T}(\mathrm{n}: 25 \mathrm{I78})$ & I.8 (444) & \\
\hline \multicolumn{4}{|l|}{ Age } \\
\hline \multirow[t]{3}{*}{$18-25$} & $M(n: 3906)$ & $0.9(37)$ & $X^{2}=10.45, d f=4, P=0.03^{a}$ \\
\hline & $F(n: 3823)$ & $2.5(96)$ & $X^{2}=8.15, d f=4, P=0.08^{b}$ \\
\hline & $\mathrm{T}(\mathrm{n}: 7754)$ & $1.7(133)$ & $X^{2}=7.54, d f=4, P=0.1 I^{c}$ \\
\hline \multirow[t]{3}{*}{$26-40$} & $M(n: 3966)$ & $0.7(26)$ & \\
\hline & $F(n: 4229)$ & $2.8(120)$ & \\
\hline & $\mathrm{T}(\mathrm{n}: 8219)$ & $1.8(146)$ & \\
\hline \multirow[t]{3}{*}{$4 \mid-55$} & $M(n: 2747)$ & 0.7 (19) & \\
\hline & $\mathrm{F}(\mathrm{n}: 2857)$ & $3.5(100)$ & \\
\hline & $T(n: 56 \mid 4)$ & $2.1(119)$ & \\
\hline \multirow[t]{3}{*}{$56-65$} & $M(n: 1050)$ & $0.8(8)$ & \\
\hline & $F(n: 882)$ & $2.4(21)$ & \\
\hline & $\mathrm{T}(\mathrm{n}: 1939)$ & $1.5(29)$ & \\
\hline \multirow[t]{3}{*}{+65} & $M(n: 954)$ & $0.1(1)$ & \\
\hline & $F(n: 705)$ & $2.3(16)$ & \\
\hline & $\mathrm{T}(\mathrm{n}: 1675)$ & $I(17)$ & \\
\hline \multicolumn{4}{|l|}{ Marital Status } \\
\hline \multirow[t]{3}{*}{ Single } & $M(n: 4203)$ & I (40) & $X^{2}=8.72, d f=3, P=0.03^{a}$ \\
\hline & $F(n: 3 \mid 32)$ & $2.1(65)$ & $X^{2}=5.22, d f=3, P=0.26^{b}$ \\
\hline & $T(n: 736 I)$ & $1.4(105)$ & $X^{2}=9.65, d f=3, P=0.02 c$ \\
\hline \multirow[t]{3}{*}{ Married } & $M(n: 8298)$ & $0.6(5 \mathrm{I})$ & \\
\hline & $F(n: 8684)$ & $3.1(269)$ & \\
\hline & $\mathrm{T}(\mathrm{n}: 17033)$ & $1.9(320)$ & \\
\hline \multirow[t]{3}{*}{ Separated or Divorce } & $M(n: 35)$ & 0 & \\
\hline & $F(n: 86)$ & $1.2(1)$ & \\
\hline & $\mathrm{T}(\mathrm{n}: 121)$ & $0.8(I)$ & \\
\hline \multirow[t]{3}{*}{ Widow/ Widower } & $M(n: 74)$ & 0 & \\
\hline & $F(n: 566)$ & $2.8(16)$ & \\
\hline & $\mathrm{T}(\mathrm{n}: 643)$ & $2.5(16)$ & \\
\hline
\end{tabular}

$M=$ Male, $F=$ Female, $T=$ Total. a: Weighted in total group b: Weighted in male subjects c: Weighted in female subjects. Discrepancy between total numbers and sum ups of male and female numbers are due to the missing data.

This research data was collected through face to face interview conducted by clinical psychologists employed throughout the country and the diagnosis was made based on DSM-IV classification. After the pilot study, a predetermined algorithm to make the diagnosis of OCD conducted the main study. The interviewers were 250 experienced clinical psychologists who had completed a rigorous program of training to administer the SADS reliably. They interviewed the predetermined subjects at home face to face.

The variables age, gender, marital status, type of occupation, educational level, and residency in urban or rural areas was examined as associated factors for OCD. A more detailed discussion of the results about other psychiatric disorders is presented in the overview of the survey [13]. The procedure for carrying out the study was approved and executed in accordance with institutional require- ments for the protection of human subjects. Prior to the interview informed consent was obtained from each respondent.

Each of the factors: sex, age, marital status, occupation, education and residential area, were considered separately as independent variable in univariate logistic regression model containing a constant term. All these factors were considered as independent variables in a multivariate logistic regression model with a constant term. The estimated coefficients, significant levels, odds ratios and 95\% confidence intervals for odds ratios are illustrated in table 4.

In indicator recoding of variables having more than two categories, the reference categories were considered as "widow/widower" for marital status, "other occupations" for occupation variable and "illiterate" for education. Age 
Table 2: Prevalence of OCD by type of occupation.

\begin{tabular}{|c|c|c|c|}
\hline Variable & & $\%(n)$ & $p$ \\
\hline \multicolumn{4}{|l|}{ Occupation } \\
\hline \multirow[t]{3}{*}{ Worker } & $M(n: 2 \mid 14)$ & $0.6(12)$ & $X^{2}=154.70, d f=7, P=0.001 a$ \\
\hline & $F(n: 149)$ & $2.7(4)$ & $X^{2}=19.03, d f=6, P=0.004 b$ \\
\hline & $T(n: 2266)$ & $0.7(16)$ & $X^{2}=8.22, d f=7, P=0.3 \mathrm{Ic}$ \\
\hline \multirow[t]{3}{*}{ Employees } & $M(n: 2105)$ & $0.8(16)$ & \\
\hline & $F(n: 625)$ & $2.4(15)$ & \\
\hline & $\mathrm{T}(\mathrm{n}: 2737)$ & I.I (3I) & \\
\hline \multirow[t]{3}{*}{ Student } & $M(n: 935)$ & $1.3(12)$ & \\
\hline & $F(n: 779)$ & $1.5(12)$ & \\
\hline & $\mathrm{T}(\mathrm{n}: 1723)$ & $1.4(24)$ & \\
\hline \multirow[t]{3}{*}{ Business } & $M(n: 4927)$ & $0.5(23)$ & \\
\hline & $F(n: 318)$ & $2.5(8)$ & \\
\hline & $T(n: 5260)$ & $0.6(31)$ & \\
\hline \multirow[t]{3}{*}{ Retired } & $M(n: 584)$ & I (6) & \\
\hline & $F(n: 126)$ & $2.4(3)$ & \\
\hline & $\mathrm{T}(\mathrm{n}: 713)$ & $1.3(9)$ & \\
\hline \multirow[t]{3}{*}{ Housewife } & $M(n:-)$ & - & \\
\hline & $F(n: 9592)$ & $3(290)$ & \\
\hline & $\mathrm{T}(\mathrm{n}: 9629)$ & $3(290)$ & \\
\hline \multirow[t]{3}{*}{ Unemployed } & $M(n: 1228)$ & $0.8(10)$ & \\
\hline & $F(n: 719)$ & $2.1(15)$ & \\
\hline & $\mathrm{T}(\mathrm{n}: 195 \mathrm{I})$ & $1.3(25)$ & \\
\hline \multirow[t]{3}{*}{ Other Occupations } & $M(n: 726)$ & $1.7(12)$ & \\
\hline & $\mathrm{F}(\mathrm{n}: 183)$ & $3.3(6)$ & \\
\hline & $\mathrm{T}(\mathrm{n}: 91 \mathrm{I})$ & $2(18)$ & \\
\hline
\end{tabular}

$M=$ Male, $F=$ Female, $T$ = Total. a: Weighted in total group $b$ : Weighted in male subjects $c$ : Weighted in female subjects. Discrepancy between total numbers and sum ups of male and female numbers are due to the missing data.

is considered as a continuous variable. Chi-square test was used to examine the association of OCD with the mentioned factors in each of the total, male and female groups separately. Since distribution of onset age in both male and female groups was not normal, the Mann-Whitney U test was used to compare the onset age of them.

\section{Results}

The sample consisted of 25180 subjects having 18 years and older. The mean and standard deviation of their age was 37.2 and 16.6 years, respectively. $50.3 \%$ of them were men and $49.7 \%$ women, $29.13 \%$ single and $67.45 \%$ married, the others were separated or divorced $(0.48 \%)$, widows $(2.54 \%)$ and undetermined $(0.40 \%)$.

Table 1 shows the prevalence of OCD by sex, age group, and marital status. The association of OCD by occupation, education, and residential areas are shown in table 2 and 3.

The mean of onset age was $21.27(\mathrm{SD}=11.84)$, ranging from 6 to 75 years. The onset age in males was 21.14 and in females 21.79 . The difference was not statistically significant $(\mathrm{Z}=-.329, \mathrm{P}=.7420$, 2-tailed $)$.
All the factors of sex, age, marital status, occupation, education, and residential area were separately examined in univariate models. Sex $(P=0.0000)$, the category "single" of marital status $(P=0.03670)$, age $(P=0.0000)$, the categories "business" $(P=0.000)$ and "housewife" $(P=$ $0.0226)$, residential area $(P=0.0000)$ showed significant effect on logistic odds of OCD, but the models did not fit the data well (Table 4).

\section{Discussion}

There are considerable differences in prevalence rates and gender ratio between studies. In the current study, the rate of OCD was $1.8 \%$. A study in German by DSM-IV, which was administered to a representative sample of 4072 persons aged 18-64 years, found that the lifetime prevalence rate of OCD was $0.5 \%$ and the twelve-month prevalence rate was $0.39 \%$ [14]. Kolada et al interviewed 3258 randomly selected adult household residents of Edmonton by using the Diagnostic Interview Schedule (DIS). The lifetime and six months prevalence rates of OCD were $2.9 \%$ and $1.6 \%$, respectively [3]. A population survey using the Composite International Diagnostic Interview (CIDI) [15] found an OCD lifetime prevalence of $0.9 \%$ in the Netherlands [16] and $0.7 \%$ in the group of adoles- 
Table 3: Prevalence of $O C D$ by type of education and residential area.

\begin{tabular}{|c|c|c|c|}
\hline Variable & & $\%(n)$ & $p$ \\
\hline \multicolumn{4}{|l|}{ Education } \\
\hline \multirow[t]{3}{*}{ Illiterate } & $M(n: 2100)$ & $0.4(8)$ & $X^{2}=12.05, d f=4, P=0.0 I^{a}$ \\
\hline & $F(n: 3739)$ & $2.5(92)$ & $X^{2}=13.93, d f=4, P=0.008^{b}$ \\
\hline & $\mathrm{T}(\mathrm{n}: 5862)$ & $1.7(100)$ & $X^{2}=15.68, d f=4, P=0.003^{c}$ \\
\hline \multirow[t]{3}{*}{ Elementary school } & $M(n: 3280)$ & $0.7(22)$ & \\
\hline & $F(n: 3435)$ & $3.3(115)$ & \\
\hline & $T(n: 6734)$ & $2(137)$ & \\
\hline \multirow[t]{3}{*}{ Secondary school } & $M(n: 3036)$ & $0.6(17)$ & \\
\hline & $F(n: 1936)$ & $2.7(52)$ & \\
\hline & $\mathrm{T}(\mathrm{n}: 4789)$ & $2.1(100)$ & \\
\hline \multirow[t]{3}{*}{ High school } & $M(n: 255 I)$ & $0.9(23)$ & \\
\hline & $F(n: 2223)$ & $3.5(77)$ & \\
\hline & $\mathrm{T}(\mathrm{n}: 4994)$ & $1.4(69)$ & \\
\hline \multirow[t]{3}{*}{ Higher educated } & $M(n:|48|)$ & $0.14(20)$ & \\
\hline & $F(n: 1033)$ & $1.5(15)$ & \\
\hline & $T(n: 2519)$ & $1.4(35)$ & \\
\hline \multicolumn{4}{|l|}{ Residential area } \\
\hline \multirow[t]{3}{*}{ Urban } & $M(n: 7965)$ & $0.9(72)$ & $X^{2}=22.33, d f=I, P=0.00 I^{a}$ \\
\hline & $F(n: 7750)$ & $2.1(99)$ & $X^{2}=10.30, d f=I, P=0.001 \mathrm{~b}$ \\
\hline & $\mathrm{T}(\mathrm{n}: 16042)$ & $2(326)$ & $X^{2}=15.56, d f=I, P=0.001 c$ \\
\hline \multirow[t]{3}{*}{ Rural } & $M(n: 4693)$ & $4(19)$ & \\
\hline & $F(n: 4770)$ & $3.3(254)$ & \\
\hline & $\mathrm{T}(\mathrm{n}: 9556)$ & $1.2(118)$ & \\
\hline
\end{tabular}

$M=$ Male, $F=$ Female, $T$ = Total. a: Weighted in total group b: Weighted in male subjects $c$ : Weighted in female subjects. Discrepancy between total numbers and sum ups of male and female numbers are due to the missing data.

Table 4: The univariate and multivariate of logistic regression results.

\begin{tabular}{|c|c|c|c|c|c|c|c|c|c|c|}
\hline \multirow[b]{2}{*}{ Variable } & \multicolumn{3}{|c|}{ Univariate Results } & \multicolumn{2}{|c|}{$95 \% \mathrm{Cl}$ for OR } & \multicolumn{3}{|c|}{ Multivariate Results } & \multicolumn{2}{|c|}{$95 \% \mathrm{Cl}$ for OR } \\
\hline & $\hat{\beta}$ & Sig. & $\hat{\mathrm{OR}}$ & Lower & Upper & $\hat{\beta}$ & Sig. & $\hat{\mathrm{OR}}$ & Lower & Upper \\
\hline Sex & -1.3864 & .0000 & .2500 & .1983 & .3151 & $-.887 \mid$ & .0000 & .4088 & .2855 & .5855 \\
\hline Age & -.0036 & .0000 & .9964 & .9903 & 1.0025 & -.0059 & .1993 & .9941 & .9851 & 1.0031 \\
\hline \multicolumn{11}{|l|}{ Marital status* } \\
\hline Single & -.5672 & .0367 & .5671 & .3330 & .9656 & -.2161 & .4968 & .8057 & .4320 & 1.5027 \\
\hline Married & -.2873 & .2681 & .7503 & .4513 & 1.2475 & -.0734 & .7887 & .9292 & .5431 & 1.5027 \\
\hline $\begin{array}{l}\text { Separated/ } \\
\text { Divorce }\end{array}$ & -.1184 & .2800 & .3268 & .0430 & 2.4858 & -1.1191 & .2820 & .3266 & .0425 & 2.5088 \\
\hline \multicolumn{11}{|l|}{ Occupation* } \\
\hline Worker & $-.77 \mid 4$ & .0502 & .4624 & .2137 & 1.0006 & -.6110 & .1378 & .5590 & .2496 & 1.2517 \\
\hline Employed & -.2962 & .0000 & .7437 & .3720 & 1.4868 & -.4280 & .2485 & .6562 & .3178 & $1.355 \mid$ \\
\hline Student & -.0867 & .8131 & .9169 & .4468 & 1.8818 & -.3592 & .3614 & .7000 & .3268 & 1.4991 \\
\hline Business & -.9510 & .0071 & .3864 & .1934 & .7718 & -.7576 & .0418 & .4728 & .2283 & .9793 \\
\hline Retired & -.1865 & .6802 & .8298 & .3418 & 2.0148 & -.1562 & .7412 & .8005 & .3218 & 1.9914 \\
\hline Housewife & .7058 & .0226 & 2.0254 & 1.1043 & 3.7149 & .0597 & .8641 & 1.1004 & .5583 & 2.1688 \\
\hline Unemployed & -.1713 & .6383 & .8426 & .4125 & 1.7212 & -.3776 & .3254 & .6795 & .3220 & 1.4340 \\
\hline \multicolumn{11}{|l|}{ Education* } \\
\hline $\begin{array}{l}\text { Elementary } \\
\text { School }\end{array}$ & .1795 & .1764 & 1.1966 & .9225 & 1.5522 & .2184 & .1342 & 1.3199 & 1.0128 & 1.7201 \\
\hline $\begin{array}{l}\text { Secondary } \\
\text { School }\end{array}$ & $-.214 \mid$ & .1746 & .8073 & .5926 & 1.0997 & -.0526 & .7768 & 1.0384 & .7531 & 1.4318 \\
\hline High School & .2061 & .1490 & 1.2288 & .9289 & 1.6257 & .2614 & .1446 & $1.406 \mid$ & 1.0368 & 1.9069 \\
\hline Higher Educated & -.2084 & .2922 & .8119 & .5509 & 1.1965 & .0139 & .9548 & 1.0947 & 6959 & 1.7222 \\
\hline Residential area & .5062 & .0000 & 1.6590 & 1.3419 & 2.0510 & .5182 & .0000 & 1.6492 & 1.3143 & 2.0616 \\
\hline
\end{tabular}

$\hat{\beta}=$ Coefficient, $\hat{\mathrm{OR}}=$ Odds Ratio, Sig. = Significant level, $\mathrm{Cl}=$ Confidence Interval. *In fact, the new categories of each variable should be renamed after indicator recoding. To make the categories more understandable, the former names were used. 
cents and young adults in Munich [17]. In addition, a cross-sectional collaborative study in seven countries estimated that the lifetime prevalence of OCD was $2 \%$ [6]. Multiple factors might be involved in differences of the prevalence with the other studies. For example, the study that was conducted in Taiwan was based on DSM-III-R criteria [6]. The diagnostic criteria, which were used in the ECA study, was based on DSM-III criteria [5].

Another possible explanation is the assessment procedure or instrument, which was used. For example, the ECA study has been criticized on the ground that lay interviewers administered it [5]. This may have led to over or underestimation of the prevalence of OCD. In the Taiwan study the same methodology was also used [6]. The interviewers of the current study were the clinical psychologists, which were trained to use SADS.

Furthermore, OCD can be fairly diverse in clinical symptoms. In addition, OCD symptoms may change over time within an individual. This heterogeneity in clinical symptoms enhances the chance that OCD may be misdiagnosed or remains unnoticed altogether.

Nearly, all of our subjects were Moslems and this is significantly different from the general population of USA and Taiwan. It is possible that bringing up in different religious upbringing makes it more likely that one will suffer from religious, sexual or aggressive obsession [18].

Considering the confidence intervals for odds ratios (OR) in univariate models imply that the variables sex and residential area have significant effect on logistic odds of OCD, the "single" category of marital status comparing to the "widow/widower" category, decreases the chance of having OCD. The "business" and "housewife" categories of the occupation variable, comparing to the "other occupations" category respectively, decrease and increase the chance of having OCD and no categories of the education variable comparing to the "illiterate" category have significant effect on the chance of having OCD.

The confidence interval for ORs in multivariate model imply that adjusting for other factors, the variables sex and residential area again have significant effect on logistic odds of OCD, but none of the marital status categories showed any significant effect. The "business" category of occupation comparing to the "other occupations" category, decrease the chance of having OCD, but the "housewife" category which had significant effect comparing to "other occupations" in univariate model did not show any effect in multivariate model. Although none of the education categories in the univariate model had any significant effect, the "high school" and "elementary school" categories comparing to the "illiterate" category increase the chance of having OCD, adjusting for other factors.

In the current study, the rates of OCD in male and female groups were $0.7 \%$ and $2.8 \%$, respectively and the difference is meaningful. Although in general the estimated OCD is equal in males and females in clinical based samples [18], an epidemiological data point to a gender ratio (male to female) of 1 to 2.3 in six month prevalence and 0.9 to 3.4 in lifetime prevalence of OCD [4]. A Study in Germany found that the gender female to male ratio of OCD was 5.7 [14].

ECA survey found that the lifetime and past-year prevalence of OCD in women was greater than men and women had a significant higher lifetime prevalence overall (3\% versus $2 \%$ ). However, this gender difference was eliminated after controlling other demographic factors $[5,19]$. In the current study, there was gender difference even after controlling the other factors.

Similarly, the cross-sectional collaborative study found a slight female preponderance and lifetime rate greater in female, in almost all countries surveyed [6]. In contrast, the Edmonton study found that women had slightly lower lifetime prevalence rates in all age groups, except 25-34 years old, where the rate in women was more than twice that in men [3]. Whereas, in the current study the rate of OCD in the all age groups, females rate was more than the males, and the rate of OCD decreased after 50 years of age. The ECA survey found the highest prevalence rate occurring in the 30-44 years age group [19].

An impression from clinical series is that OCD patients are less likely to get marry or if they do, to have substantial maladjustment [20]. However, in a clinical study, Coryell did not find any differences in marital status between patients with OCD compared to a matched control group of patients with unipolar depression [21]. In contrast, the ECA study, showed that after controlling the other sociodemographic factors, the prevalence of OCD was significantly higher in subjects who had been separated or divorced, and was lowest in stable marriage subjects and intermediate in subjects who had been separated or divorced $[5,19]$.

In the current study, the association of OCD with marital status was significant and the rate was higher in subjects who had been widowed, and lowest in divorced or separated subjects, and intermediate in single or married subjects but, after controlling the socio-demographic factors, the prevalence of OCD was not significantly different between the marital statuses. This is in contrast with prior studies $[5,19]$. These findings may suggest that individuals with OCD may not be less likely to marry and procreate 
or have not stable marriage. Although, clarification of this issue requires studies, which evaluate personality characters, severity of OCD, course and treatment, are received, therefore, this finding is in contrast with Hafner study [20].

There was an association between educational level and OCD. However, educational level is not a risk factor of OCD; prvious epidemiological studies have not found that subjects with OCD are of higher educational level. In ECA study, the prevalence of OCD was greater in subjects who failed to complete a given level of schooling $[5,19]$. Also, in Tehran province the rate in high educated individuals is lower [22]. In accordance with them, most OCD subjects in the current study were in lower educational levels.

The frequency of OCD in urban areas is more than rural areas. Residential area is a risk factor of $\operatorname{OCD}(13,22)$. However, rural life has dramatically changed over the past 2 decades and the traditional characteristics of rural life have been affected by factors such as economic restructuring, movement of the younger generation to cities, having easy access to information such as the internet, and ready access to urban settings by improved transportation. Therefore, we should probably not focus on the quantitative questions of whether disorders are more or less common in urban than rural areas.

There is a significant association between occupation and OCD and it is a risk factor for OCD in Iran. However, in the ECA study, there was little difference between OCD and non-OCD subjects in terms of current unemployment or type of occupation or job states. However, the prevalence of OCD was greater in subjects who had been unemployed for at least 6-months over the prior five years $[5,19]$. In our study, the rate of OCD in subjects who were unemployed was less than housewife subjects. May be this is one of the major differences between the two studies.

In almost all clinical and epidemiological surveys of adults, the majority of cases of OCD have onset age before the age of $26[14,20,23]$. It seems that our results are in concordance with the previous studies. The comorbidity of OCD with other psychiatric disorders, gender-specific phenomenology of the OCD symptoms and degree of impairment will be presented in further article.

\section{Conclusions}

The prevalence study suggests that the prevalence of OCD is not rare in the community of Iran and it is in the range of other countries. As in prior studies in Iran's communities, OCD is more common in females than males. There is a significant association between occupation and OCD and the rate of OCD in unemployed subjects was less than householders.

\section{Competing interests}

None declared.

\section{Authors' contributions}

Mohammad Reza Mohammadi (principal investigator and designer, psychiatrist)

Ahmad Ghanizadeh (investigator, psychiatrist)

Mehdi Rahgozar (statistical analysist and programmer, biostatistician)

Ahmad Ali Noorbala (designer, psychiatrist)

Haratoun Davidian (designer, psychiatrist)

Hossein Malek Afzali (statistical consultant, biostatistician)

Hamid Reza Naghavi (coordinator and investigator, psychiatrist)

Seyed abbas Bagheri Yazdi (investigator, clinical psychologist)

Seyed Mehdi Saberi (investigator, psychiatrist)

Bita Mesgarpour (investigator, pharmacist)

Shahin Akhondzadeh (investigator, clinical neuropsychopharmacologist)

Javad Alaghebandrad (investigator, psychiatrist)

Mehdi Tehranidoost (investigator, psychiatrist)

\section{Acknowledgements}

This research was supported by a grant from the Medical Commission of National Scientific Research Council and the National Research Center of Medical Sciences of Iran. We appreciate the contributions and participation of the individuals and their families. We also grateful to Prof Kazem Mohammad the project supervisor, Dr. Hamid Reza Pouretemad, Dr. Homayoon Amini, Dr. Omran Mohammad Razaghi, Dr. Mohammad Taghi Joghataie, Dr. Ali Kalantar Motamed, Julia Safari and 250 clinical psychologists and experts who assisted us in conducting this national survey.

\section{References}

I. Rudin G: Ein Beitrag zur Frage der Zwangskrankheit, insbesondere ihrer herditaren Beziehungen. Arch Psychiat und Z ges Neurol Psychiat 1953, I 9 I: |4-54.

2. Woodruff R, Pitts FN Jr: Monozygotic twins with obsessional illness. Am J Psychiatry. 1964, I 20:1075-1080.

3. Kolada JL, Bland RC, Newman SC: Epidemiology of psychiatric disorders in Edmonton. Obsessive-compulsive disorder. Acta Psychiatr Scand Suppl. 1994, Suppl 376:24-35. 
4. Bebbington PE: Epidemiology of obsessive-compulsive disorder. BrJ Psychiatry 1998, Suppl 35:2-6.

5. Karno M, Golding JM, Sorenson SB, Burnam MA: The epidemiology of obsessive-compulsive disorder in five US communities. Arch Gen Psychiatry. 1988, 45:1094-1099.

6. Weissman MM, Bland RC, Canino G], Greenwald S, Hwu HG, Lee CK, Newman SC, Oakley-Browne MA, Rubio-Stipec M, Wickramaratne PJ, Wittchen HU, Yeh EK: The cross national epidemiology of obsessive compulsive disorder. The Cross National Collaborative Group. J Clin Psychiatry. 1994, Suppl:5-10.

7. Rasmussen SA, Eisen JL: Coexisting obsessive compulsive disorder and alcoholism. I Clin Psychiatry 1989, 50(3):96-98.

8. Rasmussen SA, Eisen JL: Epidemiology of obsessive compulsive disorder. J Clin Psychiatry 1990, 5 I (Suppl): 10-3.

9. Kaplan HI, Sadock B]: Kaplan and Sadock's Synopsis of Psychiatry: Behavioural Sciences, Clinical Psychiatry. 8th edition. Lippincott: Williams and Wilkins; 1991.

10. Endicott J, Spitzer RL: A diagnostic interview: the schedule for affective disorders and schizophrenia. Arch Gen Psychiatry 1978, 35(7):837-844.

II. American Psychiatric Association: Diagnostic and Statistical Manual of Mental Disorders (DSM-IV). 4th edition. Washington DC; 1994.

12. Leboyer M, Maier W, Teherani M, Lichtermann D, D'Amato T, Franke $P$, Lepine JP, Minges J, McGuffin P: The reliability of the SADS-LA in a family study setting. Eur Arch Psychiatry Clin Neurosci 199I, 24I(3): 165-169.

13. Mohammadi MR, Davidian H, Noorbala AA, Malekafzali H, Naghavi HR, Pouretemad HR, Bagheri Yazdi SA, Rahgozar M, Alaghebandrad J, Amini H, Razaghi OM: An epidemiological study of psychiatric disorders in Iran, 200 I. J Hakim 2003, I:55-64.

14. Grabe HJ, Meyer C, Hapke U, Rumpf HJ, Freyberger HJ, Dilling H, John U: Prevalence, quality of life and psychosocial function in obsessive-compulsive disorder and subclinical obsessivecompulsive disorder in northern Germany. Eur Arch Psychiatry Clin Neurosci 2000, 250(5):262-8.

15. Robins LN, Wing J, Wittchen HU, Helzer JE, Babor TF, Burke J Farmer A, Jablenski A, Pickens R, Regier DA, Sartorius N, Towle LH: The Composite International Diagnostic Interview. An epidemiologic Instrument suitable for use in conjunction with different diagnostic systems and in different cultures. Arch Gen Psychiatry 1988, 45( I 2): 1069-1077.

16. de Graaf R, Bijl RV, Smit F, Ravelli A, Vollebergh WA: Psychiatric and sociodemographic predictors of attrition in a longitudinal study: The Netherlands Mental Health Survey and Incidence Study (NEMESIS). Am J Epidemiol 2000, I 52(I I): 1039-1047.

17. Wittchen HU, Nelson CB, Lachner G: Prevalence of mental disorders and psychosocial impairments in adolescents and young adults. Psychol Med 1998, 28(I): 109-126.

18. Rasmussen SA, Eisen JL: The epidemiology and clinical features of obsessive compulsive disorder. Psychiatr Clin North Am 1992, I 5(4):743-758.

19. Karno M, Golding JM: Obsessive-compulsive disorder. In Psychiatric disorders in America: The epidemiologic catchment area study Edited by: Robins LN, Regier DA. New York: Free Press; 1991:204-219.

20. Hafner RJ, Miller RJ: Obsessive-compulsive disorder: an exploration of some unresolved clinical issues. Aust N Z J Psychiatry 1990, 24(4):480-485.

21. Coryell W: Obsessive-compulsive disorder and primary unipolar depression: Comparisons of background, family history, course and mortality. J Nerv Ment Dis 198I, 169:220-224.

22. Mohammadi MR, Rahgozar M, Bagheri Yazdi SA, Naghavi HR, Pour Etemad HR, Amini H, Rostami MR, Khalajabadi Farahani F, Mesgarpour B: An Epidemiological Study of Psychiatric Disorders in Tehran Province (Year 200I). J Andisheh Raftar in press.

23. Shooka A, al-Haddad MK, Raees A: OCD in Bahrain: a phenomenological profile. Int J Soc Psychiatry 1998, 44: 147-54.

\section{Pre-publication history}

The pre-publication history for this paper can be accessed here:

http://www.biomedcentral.com/1471-244X/4/2/prepub

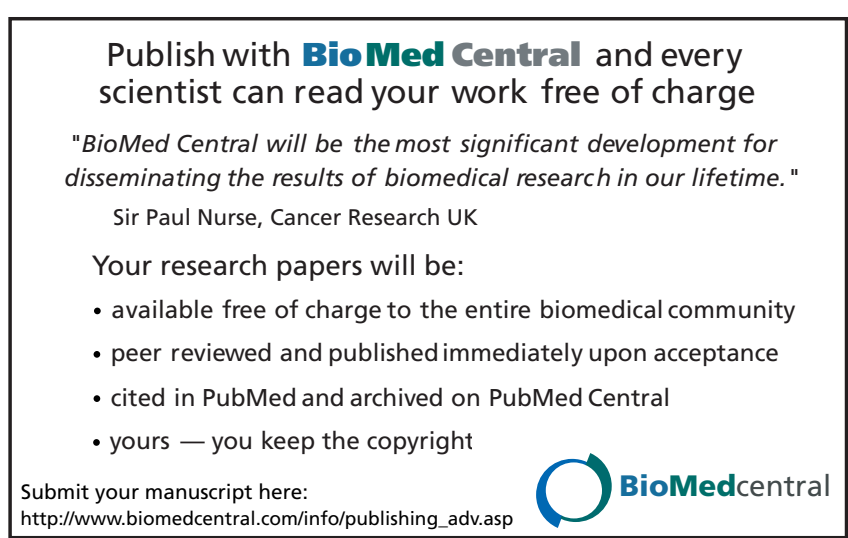

